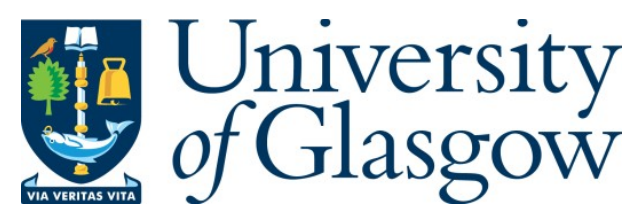

Enslin, P., and Tjiattas, M. (2015) Getting the measure of measurement: global educational opportunity. Educational Philosophy and Theory, (doi:10.1080/00131857.2015.1048667).

There may be differences between this version and the published version. You are advised to consult the publisher's version if you wish to cite from it.

http://eprints.gla.ac.uk/106315/

Deposited on: 19 May 2015

Enlighten - Research publications by members of the University of Glasgow http://eprints.gla.ac.uk 


\section{Getting the Measure of Measurement: Global Educational Opportunity}

\section{The use and misuse of measurement}

'Not everything that counts can be counted and not everything that can be counted counts.' (Einstein, attributed by Scott \& Light, 2004, p. 135)

Too many issues, activities, procedures and standards in education are corrupted by the inappropriate use of numerical measurement. The spectacular achievements of mathematics and physics in creating order through accurate measurement of time, distance, weight, height, length and speed have, unsurprisingly, encouraged social scientists, psychologists and educators to emulate such success. Pursuit of mechanical measures of quality is pervasive, and has infiltrated educational institutions (as manifested for example in the prominence of citation indices in the evaluation of academic research and league tables in rating schools and universities). The appeal is not difficult to explain. Given the importance of education as a factor affecting individual life-choices, an objective, scientific measure of quality is considered to be invaluable. 'The seductiveness of such measures is that they all turn measures of quality into measures of quantity, thereby allowing comparison across cases with a single metric' (Scott \& Light 2004, p. 119).

The seeming availability of a univocal, objective measure is, according to Scott and Light, one important aspect of the problem: the measures are of questionable validity since they do not capture what they purportedly are concerned to measure - viz., quality. But the deeper concern, they note, is that democratic forms of reasoning about standards and the value of knowledge fall prey to technical calculation lacking in scientific validity and moral justification (p. 119). Even if the scientific validity of the measures could be secured (presumably by employing sound rules of aggregation and selecting correct metrics that would provide relevant information), this would not be a sufficient guarantee of reliability. This is because such measures 'colonize' behaviour (Scott \& Light, 2004, p. xx), creating new kinds of ways for people to be. Such concerns do not show that numerical information has no role in a process of reasonable deliberation. But Pogge sums up the obvious caution well: we should be aware of 'carefully made-up statistics that keep us comfortably ignorant of what we are doing' (2010a, p. 2). We need to employ established and proposed measures cautiously, and remain vigilant with respect to their role in public deliberation.

Despite these cautions, we argue that some things that count can and should be counted. By various measures, global poverty and associated inequality in educational opportunity is an injustice. In Australia, the country ranked second on the Human Development Index (HDI) in 2012, life expectancy at birth was 82 years, while mean years of schooling enjoyed by Australians was 12 years. By contrast, in bottom-of-the-table Mozambique, life expectancy was measured at 50.7 years and mean years of schooling 1.2 years (UNESCO, 2013). Similar raw disparities are evident in the huge differences in educational expenditure and participation rates between developed and developing countries reported in the monitoring reports of the Education for All campaign, in association with the Millennium Development Goals (e.g. UNESCO, 2013/14).

Even more compelling evidence of the power of measurement of inequality, because it brings out the way in which numbers can indicate significance and potential for action, is the 
evidence that Pogge (2010a) presents about global poverty and what quite modest redistribution from developed to developing countries could do to relieve it:

Although 48 percent of the world's population, 3,085 million human beings, were reportedly living below [the World Bank's $\$ 2.50$ a day] poverty line in 2005...their collective shortfall from this line amounts to only 2 percent of global household income. A 2 percent shift in the distribution of global household income could wholly eradicate the severe poverty that currently blights the lives of nearly half the human population. (Pogge, 2010a, p. 12)

Numerical measurements like these say a lot about global inequality, in which poverty and education are closely interrelated. The high levels of literacy and numeracy that are essential to development 'come only with free and compulsory public education' (Okin, 2003, p. 290). In many situations education can contribute to increased incomes. When children's labour is necessary to household income they are likely to go without education. If malnourished or ill and unable to afford treatment they may miss school or learn less successfully. 'If a woman works a seventeen hour day, she cannot take advantage of the literacy program that might otherwise improve her earning power or enable her to find out about her legal rights or government programs or services she could qualify for' (Okin, 2003, p. 305).

Inequalities in educational opportunities between rich and poor countries, we have argued (Blind review), imply cosmopolitan duties of justice that require global redistribution of educational resources. In focusing now on the role of measurement in pursuit of more just global educational opportunities, we explore the significance of quantitative information when asking distributional questions. Numbers are clearly important in handling such questions, for justice is largely about distribution (Blind review). So numerical information is apt, if not indispensable. And numerical indices allow for it to be presented in a form that is amenable to policy and decision-making in large-scale contexts.

Yet in view of widespread recognition that numerical measures have been misused in the service of promoting questionable objectives in education, how can a case be made for their legitimate use in normative, and especially moral, analysis? Our discussion begins (section 2) with an illustration of the way in which metrics have featured in the formulation of theories of justice in political philosophy. Specifically, we examine the ways in which Rawls and Sen conceptualize the metric of social justice, survey more applied accounts of their theories, and proceed to analyses of what Pogge calls 'morally plausible' indices of equity. Arguing for a widened notion of counting, we then explore (section 3) three means of addressing global inequality. We defend a reconstruction of the public sphere in which objective measures of justice, deliberatively constructed, could supersede prevalent assumptions about measurement (section 4). In defending measurement, understood both qualitatively and quantitatively, normatively and numerically, as having an important role in deliberations about justice in education, we suggest that debates about the appropriate metric of justice are, crucially, about the normative foundations of justice.

\section{Justice: which metric?}

Some preliminaries 
The justifiability of distributional principles depends in part on the rules of aggregation they employ, as brought out in discussions (e.g. Parfit, 2013; Scanlon, 1998) about the justifiability or otherwise of additive aggregative principles of reasoning, most prominently employed in utilitarian thought, which attempts to measure the goodness of states of affairs by summing benefits and harms across individual lives and discounting distributional considerations. Utilitarianism often functions as the paradigmatic way of giving numerical considerations significance in practical reasoning. But its prominence is also responsible for the prevalent assumption that allowing numbers to count in normative deliberation is inevitably accompanied by a non-distributional view of the goodness of states of affairs. However, as several philosophers insist, these should be taken to be independent considerations. $^{1}$

The important point here is that indices, used 'as proxies for values that political actors of various kinds purport to measure’ (Pogge, 2010a, pp. 76-77), required in order to evaluate and compare states of affairs, need to be constructed so that they reflect, isolate and point to, and amalgamate morally relevant factors. As such, indices are inescapably normative. In political philosophy, indices are readily associated with the work of such prominent figures as Rawls, Sen and Pogge. In Rawls’s succinct formulation (1982, p. 364), the index of primary goods 'defines a public basis of interpersonal comparisons for questions of social justice.' Of course, as he himself points out (1982, p. 373), evaluations making use of indices are variable. '...we make interpersonal comparisons in many different contexts and for many different purposes; each context has its relevant considerations according to the appropriate ends in view. On birthdays we give things that we know are wanted, or that will please, to express affection...' Citizens (conceived as free and equal moral persons) require primary goods, and justice requires distribution according to those needs (Rawls, 1982, p. 374). Since we are centrally concerned with principles of distribution, we are concerned with those theories which primarily evaluate states of affairs with respect to just distribution.

Our central question is thus, 'What is the proper metric of justice?' In other words, 'What should we look at when evaluating whether one state of affairs is more or less just than another?' (Brighouse \& Robeyns, 2010, p. 1).

\section{Resources or Capabilities}

Theories of justice, which have set out to provide independent, cross-cultural measures of the goods required for well-being, are an obvious source of candidates for the proper metric of justice. The most well-known and influential of all, Rawls's (1971) account of just distribution, explicitly includes an index of primary goods (basic liberties, powers and prerogatives of offices of responsibility, income and wealth, social basis of self-respect), or resources, those goods which anyone would need, whatever else they wanted, the all-purpose means to a wide variety of ends, and the principles according to which these are to be distributed. Such an index, Rawls believes, allows us to make interpersonal comparisons with respect to social justice (1982, p. 359). Rawls's hypothetical contractors in the original position, behind a thick veil of ignorance, are given the task of choosing, in the form of principles of justice, fair terms of cooperation. The index of primary social goods serves, for them, as a 'thin theory of the good', which they use to measure their life-long prospects, how well off they would be, regardless of who they turn out to be when the veil is lifted. The use of primary goods in making interpersonal comparisons in questions of social justice rests on the conception of moral persons (Rawls, 1982). Parties '...best represent citizens as free and equal moral persons by deciding between alternative principles of justice according to how 
securely these principles provide for all citizens the primary goods' (Rawls, 1982, p. 366). Justice requires distribution according to citizens' needs as free and equal moral persons who try to realize their conceptions of the good. The principles of justice are rules that determine how these goods are to be distributed.

Anderson (2010) helpfully breaks down the two main constituents of theories of distributive justice: they must, she insists, specify two things: a metric, which characterizes the type of good subject to demands of justice, and a rule that determines how the good should be distributed. Different theories of justice may thus be compared with respect to these: utilitarianism proposes a subjective metric (happiness, preference satisfaction) as opposed to both Rawlsians and capability theorists who propose objective metrics (resources and functionings respectively). Deliberations about social justice can never dispense with qualitative reasoning; counting can never be a proxy for this, although it can be a very useful aid to reflective evaluation (Anderson, 2010). Questions about the metric of social justice attempt to find out what the appropriate informational basis of evaluations should be taken to be. Sen (2009, p. 291) reminds us that 'Every normative theory of social justice demands equality of something - liberty, income, equal treatment of everyone’s rights'. It proposes an informational focus or metric: utilitarianism concentrates on individual happiness, pleasure, or 'utility' as the best way of assessing individual well-being, Sen (2009) takes capability as a basic informational ingredient, and Rawls believes social primary goods provide the informational basis for evaluations concerning just distribution. Ultimately, the plausibility of the metric is intrinsically tied to the theory of justice from which it derives. Theories of justice also provide rules about how the goods specified by the metric are to be distributed to meet requirements of justice. Rawlsians and capability theorists propose procedural and distribution-sensitive rules, while utilitarians insist on rules that sum and maximize the good — and are pattern-insensitive.

Rawls's theory provides for assessment of outcomes that is much more complex than the simple additive aggregation of utilitarianism. Fairness is a function not simply of the maximization of happiness or desire satisfaction, but, crucially, of their distribution, and goods are defined with respect to what citizens require in order to realize their nature as moral persons.

The now standard alternative to Rawls's metric is provided by the 'capabilities approach' of Sen and Nussbaum, who propose that the 'currency of justice' is fundamental human capabilities or functionings, rather than social primary goods. The latter, they believe, in failing to track the diverse ways in which people are able to use goods to achieve their ends, stops short of ensuring well-being and the opportunity to realize positive freedom (Nussbaum, 2007; Sen, 2009). This is because people have varying needs for resources and different abilities to convert resources into functioning. The value of resources lies in how they promote human functioning: the focus in evaluating just distribution is on the personal characteristics (capabilities or substantive freedoms) that govern conversion of primary goods into a person's ability to promote her ends, rather than on a standard set of resources at her disposal. Sen has argued that the primary goods metric is too inflexible to take account of the diversity of needs, varying with health, longevity, location. Thus, for Sen, the Rawlsian metric, which focuses on means rather than on actual opportunities of living, fails to capture the differential advantages enjoyed by people with different capacities to convert primary goods into functionings, and so allows for 'unjustified inequality' (Sen, 1990, p. 112). For both Nussbaum and Sen the 'space' of justice is that of capabilities, rather than opportunities. 
We shall not attempt to adjudicate the dispute about the reducibility or otherwise of one of these positions to the other, but we do take them to be notational variants, differing in emphasis or on minor details. ${ }^{2}$ Both are illuminating when applied to justice in education. Education viewed in Rawlsian terms as a social primary good is also likely to lead to the acquisition of other primary goods like employment and income. A resourcist approach is amenable to measurement of opportunity, in the form of expenditure, school attendance, provision of classrooms, learning materials and qualified teachers. The capability approach in turn exposes some limitations of a resourcist view of educational opportunity by showing how persons are differently placed to benefit from educational opportunities, by varying personal attributes and circumstances that may favour or impair their converting opportunities into outcomes. The capability approach demonstrates that outcomes in the form of capabilities and functionings, which are less amenable to numerical measurement, are also a crucial facet of equal opportunity. But learning outcomes can be especially vulnerable to educationally inappropriate forms of measurement that colonize and corrupt what they are supposed to promote. And some intrinsically valuable benefits of educational opportunities, whether formal, non-formal or informal, are not measurable by any index.

\section{Objectivity and Metrics}

Sen asks: 'In what way can diagnosis of injustice or identification of what would reduce or eliminate it be objective?' Demands of objectivity call for objective reasoning in thinking about issues of justice and injustice (Sen, 2009, p. 41), and in turn to public reasoning (2009, p. 122). Sen recognizes the importance of Rawls's work (e.g. 1971) in drawing attention to the point that judgements of justice can't be an entirely private affair, and that a 'public framework of thought' is critically important. Both Rawlsian and capability theories of justice are committed to objective notions of the good in matters of just distribution. This is a major difference between them and utilitarian accounts of justice. They both hold that the standard of objectivity of ethical principles is 'basically congruent with their defensibility within a public framework of thought' (Sen, 2009, p.134). But several commentators (e.g. Pogge, 2010b) have pointed out that Sen's insistence on a public framework is in tension with the insistence on sensitivity to the variable capacity sought by capability theorists. Pogge (2010b) believes that capability theory does not yield an informationally workable metric, because it cannot function as a public criterion of social justice. Kelly (2010) concurs that Sen's proposed metric does not seem to lend itself to the construction of a public common standard of measurement for interpersonal comparisons as readily as Rawls's (1971) notion of primary goods: Rawls thus provides a much stronger basis for meeting the publicity requirement. Kelly finds it difficult to conceive of '...how a common standard of measurement could be constructed' if claims of distributive justice focused on welfare or 'functionings' (2010, p. 62). On the other hand, the notion of primary goods '...provides a public and readily quantifiable measure for interpersonal comparisons.' In addition, by circumventing appeals to contested conceptions of the good, the metric of primary goods provides a basis for public decision-making.

\section{Morally plausible metrics}

There is a growing interest among political and policy theorists in indices, both as instruments for aggregating information and as standards of evaluation. But if indices are to capture phenomena of normative interest (e.g. poverty, gender equality) rules of aggregation and metrics need to be appropriate so as to base evaluations on relevant information. ${ }^{3}$ 
Sen's landmark work, Development as Freedom (1999) is an incisive critique of many World Bank policies and led to changes in how the UN measures development (in various Human Development Reports from 1990 onwards). For Sen, meaningful development can't be equated with economic growth '...or measured in the readily calculable ways preferred by most economists, but must take account of how people are capable of functioning...' (Okin, 2003, p. 289). Development is gauged instead with respect to the expansion of people's freedoms.

Due to the work of Sen and his colleagues, the capability approach has been operationalized by UN and various national governments and adopted by many policymakers and economists. The capability approach has enjoyed much attention and influence, having captured the attention of international agencies and nongovernmental organizations, largely as a result of the fact that the United Nations Development Program (UNDP) has adopted scores on the Human Development Index (HDI), which is a capability metric worked out in collaboration with Sen, rather than GNP per capita as its official comparative measure.

More generally, development economists are now rethinking goals and measurement of economic development. Okin points to work that registers the neglect of '...well-being, freedom, capacities, functioning and voices of the world's women, especially the poorest' (Okin 2003, p. 288). The 'feminization of global poverty', Okin claims, has not been well served by standard economic measures that take the family as their basic economic unit and do not disaggregate data with respect to individual members. Treating each household as a 'black box', these measures have failed to detect the extent of gender inequality, since they are insensitive to intrafamily distributions. In addition, economic productivity is measured in terms of labour, goods, services bought and sold in the marketplace, and excludes measurement of reproductive labour.

The HDI allows for quality of life comparisons across nations to be made in a way that captures data about individual rather than aggregate well-being. Annual Human Development Reports use concepts of functionings and capabilities as one of their theoretical cornerstones (UNDP). More than 500 regional Human Development Reports have been published. In Britain work done for the Equality and Human Rights Commission builds on and extends the capability approach (e.g. Equality and Human Rights Commission, 2011).

Some critics like Pogge (2010a), however, believe that the UN's HDI, though apparently more comprehensive and multidimensional (degree of development of each nation is calculated as the average of three components: life expectancy at birth (L), education (E), and gross domestic product (GNP) per capita (P)), is still defective insofar as it is a measure that applies to countries rather than individuals. It fails to capture information about distribution within populations. It does not capture the extent and depth of human deprivation. Of most concern is that flawed indices misdirect policy makers (Pogge, 2010a). Pogge's positive suggestion is that, in order to do better in constructing indices, interpersonal aggregation should be performed only after the relevant aspects of each person's situation have been holistically assessed. The idea is that a holistic measure of individual deprivation, grounded in a sound conception of basic human needs/requirements/capabilities, can be used in a range of different aggregation exercises without swamping information concerning individuals and their circumstances.

Recent Human Development Reports have responded to criticisms of early constructions of the HDI, changing the factors taken into account, the weighting of factors, and how they 
relate to one another. The HDI also acknowledges the need for measurement of poverty within developed states: the 2013 Human Development Report observes (p. 2), that '[t]here is a south in the north and a north in the south'.

\section{Making what counts count}

What counts, who counts?

Despite Einstein's warning (Scott \& Light, 2004, p. 135) against the assumption that all things that count can be counted and conversely that all things that can be counted count, the evidence of recent debates about metrics of justice suggests to us that some important things that count can be counted and that if informed by proper philosophical reflection the counting is getting better. Perhaps 'we are at least working in the right place and looking at the right thing', as Nussbaum observes of the Human Development Reports (Nussbaum, 2002, p. 135). As indices improve and debates about their merits embrace wider publics, so we could reduce the chances of colonizing the very goods and outcomes that we set out to measure, in addressing both global poverty and the unequal educational opportunity that it reflects and reproduces.

The Education for All Global Monitoring Reports present evidence of both the dangers of colonization and of refinement of indices used to measure inequality and progress in alleviating it. Although the number of children not in school fell by almost half from 107 million to 57 million between 1999 and 2011 (UNESCO 2013/4), states' pursuit of enrolment targets has been at the expense of quality education, for the basics have not been learned by an estimated 250 million children (UNESCO, 2013/4). Looking ahead to the post-2015 framework, the 2013/4 Global Monitoring Report implicitly responds to the colonization effect generated by targeting bigger numbers of children in schools, observing that the emphasis has as a result shifted from increasing enrolments to regarding quality education as central. While enrolments have improved, pupil-teacher ratios have barely changed. Raw enrolment measures will need to be read alongside progression rates, data on completion of primary school, and assessments of learning. Children in countries that do not yet produce these kinds of measures are not counted, nor are children not in school in countries that do produce data on assessments of learning taking place in schools. Much more work needs to be done to disaggregate the data, e.g., to 'distinguish clearly between children from advantaged and disadvantaged households’ (UNESCO, 2013/4, p. 91).

Whatever progress has been achieved so far, the Millennium Development Goal of universal primary education as 'Education for All' will not be achieved. As noted earlier, in comparing measures of poverty and access to schooling in Australia and Mozambique, vastly unequal resources and opportunities indicate that global redistribution is needed. Redistribution of resources would create enhanced opportunities to develop literacy, numeracy, information, skills and the critical perspectives individuals and societies need to exercise their will through their participation in global public reason, as well as in viable economies, on equal terms with others. Such public reason, if it includes debates about global justice, its metrics and measures, will require a numerate and literate global population.

Further progress towards better measures, in the sense of both indices and associated policies, demands a widened notion of counting. As well as being critically vigilant about counting what can both be counted and is worth counting, who counts, how do they count, and under what conditions is the counting done? We bear these underlying questions in mind in now 
discussing what measures ought to be taken to create a global order that measures up normatively, considering three means of addressing inequalities in the global distribution of resources: redistribution through individual and institutional action; structural changes in the global order; and counting the voices of the poor.

\section{Redistribution}

Global inequality is huge and growing, both between countries (Pogge, 2010a) and between rich and poor within countries (Piketty, 2013). Possible remedies to global inequalities between countries have been proposed by both resourcists and capability theorists, as well as by utilitarians (e.g. Singer, 2009). One such remedy is explicitly distributive, for example Pogge's (2010a) claim that the poverty gap could be erased if global household income were redistributed by a shift of 2 percent). Varying measures have been proposed to effect such a shift. Recommending that rich nations agree to allocate 1 percent of their GDP to address this gap, Nussbaum (2004, p. 16) argues that 'Prosperous nations have responsibility to give a substantial portion of their GDP to poorer nations' (emphasis in original), as they have responsibilities to develop the capabilities of citizens of poorer countries as well as their own. Young (2011) supported the view that absolute poverty in the world could be eliminated if only the richest nations were to devote 0.7 percent of GNP to and for the world's poor.

Redistribution of wealth from rich to poor countries could take the form of voluntary contributions by individuals (Singer, 2009). Voluntary philanthropy on the part of those who can afford to give does pose some practical problems, such as which charitable organisations can be trusted to direct donations to those most in need and for projects that do improve the conditions of the world's poorest people. A well rehearsed philosophical problem is how we might ensure that all who could contribute will do so; why would some who can afford to contribute do so if others similarly placed decline to do so? Global poverty is a structural problem that demands structural solutions, not one that can be adequately addressed through individual action.

\section{Structural change}

In his account of the kinds of institutional reforms that would count, Pogge is skeptical about the role of individual action through such measures as affluent citizens' donations. Because the international rules that govern national and international economic transactions 'are the most important causal determinants of the extent and depth of severe poverty and other human rights deficits' (2010a, p. 52), global structural reform rather than 'aid' is his preferred option. It would also cost affluent citizens less and would be more likely to be supported than donations. This kind of agency requires at least that global citizens in rich countries exercise institutional negative duties, because 'citizens may be implicated when social institutions they uphold foreseeably produce an unavoidable human rights deficit on a regular basis' (2010a, p. 29). Such deficits, Pogge argues, can be attributed to institutional factors. These include both the actions of global institutions and institutional arrangements in developing countries, controlled by economic and political elites for their own gain, frequently with the connivance of multinational companies, and agencies and governments of developed countries, e.g. through bribery and resource privilege (2010a, p. 47f). Structural reforms, 'Even small changes in the rules governing transnational trade, lending, investment, resource use, or intellectual property can have a huge impact on the global incidence of lifethreatening poverty.' (p. 53; see also p. 55) 
Nussbaum (2004) believes that we all share a collective duty to address the entitlement of all human beings to the development of the capabilities ${ }^{4}$ she lists. But she too regards creating appropriate institutional structures as more suitable than looking to individual efforts (2004, pp. 14-15) — including among these structures domestic organizations, multinational corporations, agencies like the World Bank and International Monetary Fund, the UN, the World Court, as well as NGOs, in a 'thin, decentralized, yet forceful global public sphere' (2004, p. 16, emphasis in original). Such a global public sphere should enable the voices of the poor to be heard and to count.

\section{Taking the voices of the poor into account}

The global poor count not only as deserving of remedial action by rich countries' individual citizens, as well as by governments and NGOs, and also corporations and global bodies that have tended to serve the interests of the developed north. A strong case has been made by both philosophers and the authors of the Human Development Reports that the voices of the poor must count in public debate about remedial change to address their needs.

Okin's account of evidence about 'what the people who comprise the least well-off quintile think about their own most pressing needs' (2003, p. 280) supports the view that listening to their voices is indispensable to addressing global injustice. Policy and practice in economic development have excluded the perspectives of the poor, especially those of women. The 1990 Human Development Report identified the need to hear women's voices early in the development of the Human Development Index, remarking (UNDP, 1990, p. 32): 'Women count - but are not counted'. Okin insists too that GDP does not measure development and that measured growth does not measure poverty reduction. Significantly for our purposes, she notes how frequently studies that do listen to the voices of the poor, especially those of women, report their wish for educational opportunities, for themselves and for their children. Nussbaum (2002, p. 135) presses support for listening to the voices of the poor further, in the direction of democratizing measurement itself: 'We need to rely on the ingenuity of those who suffer from deprivation: they will help us find ways to describe, and even to quantify, their predicament'.

Voice continues to feature strongly in recent Human Development Reports. The 2013 Report emphasises the importance of enabling citizens, including the youth, to participate by giving voice to their views and needs (UNDP, 2013). Unjust governance systems compound unjust and inequitable socio-economic conditions because they are monopolised by the wealthy and the powerful, excluding the voiceless (p. 37). The Human Development Reports often note the link between education and political empowerment: 'Trends conducive to empowerment include the vast increases in literacy and educational attainment in many parts of the world that have strengthened people's ability to make informed choices and hold governments accountable' (UNDP, 2010, p. 6).

\section{For good measure: disaggregating global political structures}

To complement our discussion, in section 2, of problems of aggregation in indices of poverty and inequality, we conclude by proposing a different form of disaggregation, of states as political units in which objectivity may be sought when public reason addresses inequalities and distribution of resources. For Pogge (2010a) the traditional distinction between international and intra-national relations is obsolete; hence he prefers the term 'global' to ‘international’ (p. 14). Charles Beitz’s earlier groundbreaking extension of Rawls’ (1971) 
principles of justice to the global sphere points the way (Beitz, 1999, p. 199): choices, whether about institutions or policies, should consider impartially the claims of every person who could be affected.

Far from following this maxim, the world actually operates through institutions, from global to local, that 'apply to people largely without their consent and which have the capacity to influence fundamentally the course of their lives' (Beitz, 1999, p. 204). The integrated global economy makes it increasingly difficult to distinguish global institutional structures from domestic structures. This interdependence led Beitz to influentially extend the theory of justice that Rawls intended for one society to a theory of global distributive justice, applying the difference principle both to the minimization of intrastate inequalities and 'to persons in the sense that it is the globally least advantaged representative person (or group of persons) whose position is to be maximized' (p. 152).

Switching the emphasis of justice, distribution, and so of politics itself from the entrenched idea of the world as comprising distinct societies constituted as states has radical implications not only for how people, poverty and unequal educational opportunities are counted. Nussbaum, Sen and Pogge, and Beitz (inter alia) envisage obligations of justice in a global politics extending beyond nation states. In this crucial respect they depart from Rawls (1971). They would all agree with Nussbaum's objection to Rawls that his statist position '...cannot defend redistribution from richer to poorer nations' (2004, p. 4). They would also insist that public reason is central to democracy and justice both domestically and globally.

Just as improved indices have required disaggregation of factors that previously seemed obviously aggregable, so too some disaggregation and reconstruction of organisations and publics responsible for counting will be needed. While much work remains to be done on feasible conceptions and structures for global democracy, several options have been put forward. Although there is widespread scepticism about the feasibility of creating formal global structures of governance (see for example Goodin, 2009), Held's (1995) theory of cosmopolitan democracy has, for example, proposed an elected assembly as an additional United Nations structure. Others (e.g. Cohen \& Sabel, 2004; Bohman, 2007) have turned to the European Union as an emergent political order whose web of procedures, such as the Open Method of Coordination, enable citizens to debate EU policies across national boundaries with other EU citizens. Bohman has also explored the potential of public sphere theory for developing global democracy through forms of distributed communication across multiple demoi (2009). Much further disaggregation and reconstruction will need to take place, of publics and organisations that could enable the global order and particular democratic regimes measure up to the demands of justice. Whatever forms such spaces and structures ultimately take, achieving objective measures of justice, in education and elsewhere, is best understood as predominantly a normative, political matter, rather than a question of perfecting numerical indices.

\section{Notes}

1. In line with our own views in this paper, Parfit (2013) for example has recently been at pains to show that by allowing numbers to count, we are not necessarily committed to discounting distributional considerations. The reason utilitarianism is deficient, he claims, is not because it gives weight to numbers, but because it ignores distributive 
considerations. A position which is duly sensitive to the latter, is not necessarily precluded from taking numbers into account, or arriving at conclusions by aggregating different factors. Aggregation need not take the form of simple summing (see also Temkin, 2009, p. 3). The elements relative to goodness of lives or outcomes can be combined non-additively as well (as in principles that accommodate distributive considerations, like maximin, that privileges the welfare levels of the worst off, adopting the alternative whose worst outcome is superior to the worst outcome of any other alternative (Rawls, 1971)).

2. See Anderson (2010), where is becomes clear in her attempt to compare resourcist and capability views that they are aligned with respect to most of the central questions making up their respective theories. Pogge (2010b) more directly asserts that the list of key determinants of quality of life that Sen (2010) lists can be represented in resourcist theories - both, Pogge claims, share a commitment to normative individualism, to the individual as the ultimate reference point for evaluating institutional orders, and so to the same aggregative function, and are similarly opposed to sum-ranking aggregation of utilitarianism. More concretely, both capability and resourcist theories of justice disaggregate data, and so can evaluate intrafamily distributions. In addition, sophisticated resourcist theories are sensitive to diversity of social and environmental context.) Several commentators (e.g. Daniels, 2010) go further, arguing that the distinction between capabilities and opportunities is not clearly sustainable. The most significant difference that Daniels and Anderson independently identify is that capability theory insists on a more demanding opportunity principle, one which is sensitive to more aspects of disadvantage than Rawls's principle.

3. The World Bank provides, in Pogge's view clear examples of how not to use indices. For example, in recording information on household consumption it ignores household composition. He also objects to its practice of adjusting the international poverty line (IPL), by changing the base year for comparing the purchasing power of currencies, switching from talk of 'number' to 'proportion' in addressing the objective of halving poverty by 2015, because it patently misrepresents progress towards attaining the UN Millennium Development Goals (2010a, p. 58). Warning against apparent achievement of progress through statistical gimmicks, Pogge observes that: 'The steady stream of happy news that World Bank delivers from the poverty frontworked into the titles less anyone miss the point-is not robust with respect to the level at which the IPL is set. This discredits the method the Bank and the UN are using to track world poverty by counting the poor' (2010a, p. 65).

4. Nussbaum (e.g. 2007) lists ten capabilities: life; bodily health; bodily integrity; senses, imagination and thought; emotions; practical reason; affiliation; other species; play; control over one's environment.

\section{References}

Anderson, E. (2010). Justifying the capabilities approach to justice, in: H. Brighouse and I. Robeyns (eds), Measuring Justice: Primary Goods and Capabilities. Cambridge: Cambridge University Press, 81-100. 
Beitz, C. (1997; 1999 edition with new afterword). Political Theory and International Relations. Princeton: Princeton University Press.

Bohman, J. (2007). Democracy Across Borders: From Demos to Demoi. Cambridge MA: MIT Press.

Bohman, J. (2009). Democratization through transnational publics: deliberation across borders, in: R. Geenens and R. Tinnevelt (eds), Does Truth Matter? Democracy and Public Space. Secaucus NJ: Springer, 149-165.

Brighouse, H. \& Robeyns, I. ( 2010). Introduction: Social primary goods as metrics of justice, in: H. Brighouse and I. Robeyns (eds), Measuring Justice: Primary Goods and Capabilities. Cambridge: Cambridge University Press, 1-13.

Brighouse, H. \& Unterhalter, E. (2010). Education for primary goods or for capabilities? in: H. Brighouse \& I. Robeyns (eds), Measuring Justice: Primary Goods and Capabilities Cambridge: Cambridge University Press, 193-214.

Cohen, J. and Sabel, C. (2004). Sovereignty and Solidarity: EU and US, in: K-H. Ladeur (ed), Public Governance in the Age of Globalization. Farnham: Ashgate, 157-175.

Daniels, N. (2010). Capabilities, opportunity, and health, in: H. Brighouse and I. Robeyns (eds), Measuring Justice: Primary Goods and Capabilities. Cambridge: Cambridge University Press, 131-149.

Equality and Human Rights Commission (2011). Developing the Children's Measurement Framework: Selecting the Indicators. London: Equality and Human Rights Commission.

Goodin, R. (2010). Global democracy: in the beginning. International Theory, 2(2), 175-209.

Held, D. (1995). Democracy and the Global Order. Cambridge: Polity.

Kelly, E. (2010). Equal Opportunity, unequal capability, in: H. Brighouse \& I. Robeyns (eds), Measuring Justice. Primary Goods and Capabilities. Cambridge: Cambridge University Press, 61-80.

Nussbaum, M. (2002). Capabilities and Social Justice International Studies Review, 123-135.

Nussbaum, M. (2004). Beyond the social contract: capabilities and global justice. Oxford Development Studies, 32(1), 3-18.

Nussbaum, M. (2007). Frontiers of Justice: Disability, Nationality, Species Membership. Cambridge MA: Harvard University Press.

Okin, S.M. (2003). Poverty, well-being and gender. What counts, who’s heard? Philosophy \& Public Affairs, 31(3), 280-316.

Parfit, D. (2013). On What Matters, v. 2. Oxford: Oxford University Press. 
Pogge, T. (2010a). Politics as Usual: What Lies Behind the Pro-poor Rhetoric? Cambridge: Polity.

Pogge, T. (2010b). A critique of the capability approach, in: H. Brighouse and I. Robeyns (eds), Measuring Justice: Primary Goods and Capabilities. Cambridge: Cambridge University Press, 17-60.

Piketty, T. (2014). Capital in the Twenty-First Century. Cambridge MA: Harvard University Press.

Rawls, J. (1982/1999). Social Unity and Primary Goods, in: S. Freeman (ed) John Rawls, Collected Papers. Cambridge MA: Harvard University Press, 359-387.

Rawls, J. (1971). A Theory of Justice. Cambridge MA: Harvard University Press.

Sen, A. (1990). Justice: Means Versus Freedoms. Philosophy and Public Affairs, 19, 111121.

Sen, A. (1999). Development as Freedom. Oxford: Oxford University Press.

Sen, A. (2009). The Idea of Justice. London: Allen Lane.

Scanlon, T.M. (1998). What we Owe to Each Other. Cambridge MA: Harvard University Press.

Singer, P. (2009). The Life You Can Save: Acting Now to End World Poverty. New York: Random House.

Scott, J. \& Light, M. (2004). The misuse of numbers, in: J. Purdy (ed), Democratic Vistas: Reflection on the Life of American Democracy. New Haven: Yale University Press, 115137.

Temkin, L. (2009). Aggregation within lives. Social Philosophy and Policy, 26 (1), 1-29.

United Nations Development Programme (UNDP) (1990). Human Development Report 1990. New York: Oxford University Press.

United Nations Development Programme (UNDP) (2010). Human Development Report 2010. The Real Wealth of Nations: Pathways to Human Development. Basingstoke and New York: Palgrave Macmillan.

United Nations Development Programme (UNDP) (2013). Human Development Report 2013. The Rise of the South: Human Progress in a Diverse World. New York: UNDP.

UNESCO (2013/4). Global Monitoring Report 2013/4: Teaching and Learning: Achieving Quality for All. Paris: UNESCO Publishing.

Young, I.M. (2011). Responsibility for Justice. New York: Oxford University Press. 